\section{Commentary: Targeting cytokinesis failure in tetralogy of Fallot: Late to the dance?}

\author{
Nicholas D. Andersen, MD, and \\ Joseph W. Turek, MD, PhD
}

Cardiomyocyte proliferation in the healthy human heart involves nuclear division of largely mononucleated cells, followed by a process known as cytokinesis. In cytokinesis, the resultant binucleated cardiomyocytes are cleaved to produce 2 distinct mononucleated cells. Liu and colleagues ${ }^{1}$ recently reported a link to cardiomyocyte cytokinesis failure in tetralogy of Fallot (ToF). Furthermore, their research suggests $\beta$-adrenergic receptor blockade can overcome cytokinesis failure in these ToF cardiomyocytes.

Olaf Bergmann, ${ }^{2}$ a renowned cardiac regenerative biologist, breaks down the findings offered by Liu and colleagues, ${ }^{1}$ recognizes limitations to the work, and addresses implications for treatment of ToF patients. Specifically, Bergmann ${ }^{2}$ condenses these discoveries to 4 major findings: multinucleation persists into the second postnatal month in ToF patients in an analysis of 12 biopsies compared with young adult specimens, ToF initiates cell cycle activity with cytokinesis failure in a single human neonatal specimen pulse-chase experiment, epithelial cell transforming 2 downregulation contributes to cytokinesis failure in transgenic mouse studies and also in neonatal ToF hearts compared with human fetal tissue without heart disease, and beta blockers increase epithelial cell transforming 2 expression and lead to effective cytokinesis in neonatal murine and cultured fetal human cardiomyocytes.

Limitations to these studies are appropriately acknowledged. Specifically, human specimen studies were

\footnotetext{
From the Duke Congenital Heart Research \& Training Laboratory, Duke University, and Duke Children's Pediatric \& Congenital Heart Center, Duke Children's Hospital, Durham, NC.

Disclosures: The authors reported no conflicts of interest.

The Journal policy requires editors and reviewers to disclose conflicts of interest and to decline handling or reviewing manuscripts for which they may have a conflict of interest. The editors and reviewers of this article have no conflicts of interest.

Received for publication May 18, 2020; accepted for publication May 18, 2020; available ahead of print June 6, 2020.

Address for reprints: Joseph W. Turek, MD, PhD, Division of Cardiovascular and Thoracic Surgery, Duke University Medical Center, 2301 Erwin Rd, DUMC 3474, Durham, NC 27710 (E-mail: joseph.turek@duke.edu)

J Thorac Cardiovasc Surg 2021;161:1591-2

$0022-5223 / \$ 36.00$

Copyright (C) 2020 by The American Association for Thoracic Surgery

https://doi.org/10.1016/j.jtcvs.2020.05.077
}

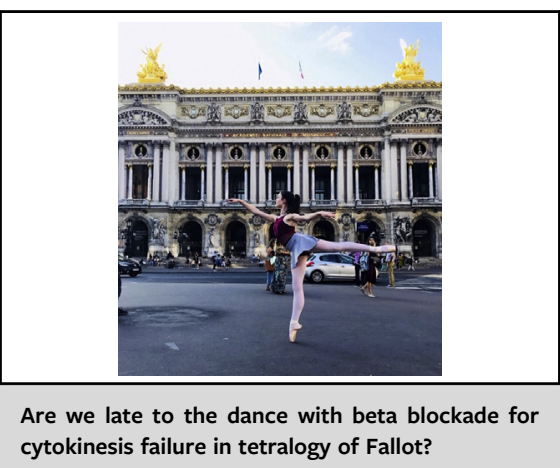

CENTRAL MESSAGE

Cardiomyocyte proliferation in tetralogy of Fallot is possibly regulated by $\beta$-adrenergic receptor-mediated cytokinesis failure, suggesting early beta blockade may be critical in treating these patients.

limited in number, making mechanistic generalizations a stretch. Moreover, in these experiments, appropriate controls were understandably unavailable (healthy human neonatal heart tissue), resulting in the use of human controls from vastly different stages of development (young adults and cultured fetal cardiomyocytes). Finally, murine cardiomyocytes are innately multinucleated, and thus their use in this work brings into question applicability to humans. These very concerns were similarly raised in a thoughtful review of the work by Liu and colleagues ${ }^{1}$ in The New England Journal of Medicine.

Clinically, these studies suggest early beta blockade in ToF patients could promote cardiomyocyte generation and serve as a surgical adjunct in reducing the risk of developing heart failure. However, Bergmann ${ }^{1}$ astutely points out that beta-blocker therapy has been used for decades in neonates with $\mathrm{ToF}$, and even studied in a randomized fashion, with no evidence of functional recovery. He hypothesizes that even with neonatal pharmacologic intervention, cytokinesis rescue may be insufficient to proliferate adequate amounts of new myocardium. In the present treatment paradigm, it would appear this is merely a laboratory phenomenon without directly translatable results to the clinical theater. This begs the question, would even earlier treatment (in utero) enable clinically relevant cardiomyocyte proliferation? Perhaps our current postnatal approach is just late to the dance. 


\section{References}

1. Liu H, Zhang C-H, Ammanamanchi N, Suresh S, Lewarchik C, Rao K, et al. Control of cytokinesis by $\beta$-adrenergic receptors indicates an approach for regulating cardiomyocyte endowment. Sci Transl Med. 2019;11:eaaw6419.
2. Bergmann O. Cardiomyocytes in congenital heart disease: overcoming cytokinesis failure in tetralogy of Fallot. J Thorac Cardiovasc Surg. 2021;161:1587-90.

3. Yutzey KE. Cytokinesis, beta-blockers, and congenital heart disease. $N$ Engl J Med. 2020;382:291-3.
See Article page 1587.

\section{Commentary: Major lessons from minor people: Beta blockers and cytokinesis in tetralogy of Fallot}

\author{
Michael J. Bonios, MD, PhD, ${ }^{\mathrm{a}, \mathrm{b}}$ \\ Eleni Tseliou, MD, $\mathrm{PhD},{ }^{\mathrm{a}}$ and \\ Stavros G. Drakos, MD, PhD, FACC ${ }^{\mathrm{a}, \mathrm{c}}$
}

Heart failure is estimated to affect more than 8 million patients in the United States. Any injury to the heart is followed by loss of cardiomyocytes. The mammalian heart has the ability to regenerate in utero following an injury. However, progressively the heart loses its regeneration capacity within the first months postnatal, with adult hearts revealing an annual regeneration capacity of no more than $1 \%$. Even following an injury, the observed increased regeneration capacity of the heart does not compensate for the myocardial loss. The occurrence of heart failure in many cases seems like an inevitable event. Bergman ${ }^{1}$ focuses on myocardial cytogenesis in patients with tetralogy of Fallot (ToF) with pulmonary stenosis (PS) during the early postnatal period. A study in this patient group has shown that $20 \%$ of cardiomyocytes did progress to karyokinesis (ie, division of nuclei) but failed to perform

From the a Division of Cardiovascular Medicine, University of Utah Health and School of Medicine, Salt Lake City, Utah; ${ }^{b}$ Heart Failure and Transplant Unit, Onassis Cardiac Surgery Center, Athens, Greece; and ${ }^{\mathrm{c}}$ Third Department of Cardiology, School of Medicine, National Kapodestrian University of Athens, Athens, Greece.

Disclosures: The authors reported no conflicts of interest.

The Journal policy requires editors and reviewers to disclose conflicts of interest and to decline handling or reviewing manuscripts for which they may have a conflict of interest. The editors and reviewers of this article have no conflicts of interest.

Received for publication June 27, 2020; revisions received June 30, 2020; accepted for publication July 6, 2020; available ahead of print July 9, 2020.

Address for reprints: Stavros G. Drakos, MD, PhD, FACC, Division of Cardiovascular Medicine, University of Utah Health, 50 N Medical Dr, Salt Lake City, UT 84132 (E-mail: stavros.drakos@hsc.utah.edu).

J Thorac Cardiovasc Surg 2021;161:1592-3

$0022-5223 / \$ 36.00$

Copyright (c) 2020 by The American Association for Thoracic Surgery

https://doi.org/10.1016/j.jtcvs.2020.07.001
Check for updates

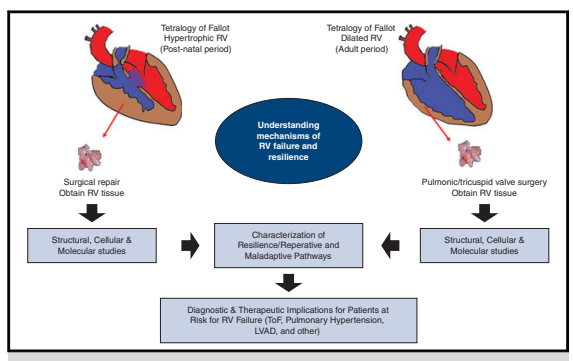

Model for advancing our understanding of mechanisms of RV failure and resilience.

CENTRAL MESSAGE

Tetralogy of Fallot recipients: A

patient population that can

teach us a lot in regard to cyto-

kinesis, regeneration, and mech-

anisms of right ventricular

resilience and failure.

cytokinesis (ie, last stage of mitosis when the new daughter cells separate from each other). ${ }^{2}$ Based on those findings, the proposed concept is to reduce beta-adrenergic signaling with beta blockers in an effort to promote the progression of karyokinesis to cytokinesis by upregulating ECT2 genes. This strategy aims to provide the heart with new cardiac myocytes, improve myocardial function, and reduce the incidence of subsequent chronic heart failure. The concept of recovering myocardial function by increasing the number of myocytes is an idea that originated a long time ago. ${ }^{3,4}$ It has been the aim of multiple preclinical and clinical studies that, in an effort to regenerate myocardium, have used various types of progenitor cells but unfortunately they have not delivered the expected results. ${ }^{5}$

Furthermore, a subset of patients with advanced chronic heart failure undergoing mechanical circulatory support with left ventricular assist devices can significantly improve their myocardial structure and function following several months of mechanical unloading. ${ }^{6}$ These findings indicate 